\title{
PELATIHAN GURU PROFESIONAL BAGI GURU SD/MI DI PALANGKA RAYA
}

\author{
(The Professional Teacher Training For The Teacher Of SD / MI In Palangka Raya) \\ Dian Lufia Rahmawati, Misyanto, dan Agung Riadin \\ Program Studi Pendidikan Guru Sekolah Dasar (PGSD) Fakultas Keguruan dan Ilmu Pendidikan \\ Universitas Muhammadiyah Palangkaraya \\ JI. RTA Milono Km.1,5 Palangka Raya, Kalimantan Tengah 73111 \\ e-mail : dianlufia25@gmail.com, misyanto40@yahoo.co.id, agung_riadin@yahoo.com
}

\begin{abstract}
Community service aims to improve the professionalism of teachers in order to become a professional teacher and can advance the quality of education in Indonesia which is currently still relatively low quality. This devotion was held on Thursday, February 18, 2016 in the Hall Regional Chairman of Muhammadiyah Palangkaraya . Target communities in this devotion is the primary school teachers in the city of Palangkaraya, the selection of schools that follow the activities carried out at random / random. The method used in this service is to provide training to teachers in elementary school and later held discussions between participants and speakers. Cost of service activities is entirely sourced from Muhammadiyah University APBU Palangkaraya Year 2015. After the implementation of this activity, it can be concluded that the trainees acquire new knowledge or to refresh back the knowledge they already have.
\end{abstract}

Keyword : Teachers, Professionals

\section{Abstrak}

Pengabdian kepada masyarakat ini bertujuan untuk meningkatkan profesionalisme guru agar dapat menjadi seorang guru yang profesional dan dapat memajukan mutu pendidikan di Indonesia yang saat ini mutunya masih tergolong rendah. Pengabdian ini dilaksanakan pada hari kamis, 18 Februari 2016 di Aula Pimpinan Wilayah Muhammadiyah Palangkaraya. Masyarakat sasaran dalam pengabdian ini adalah guru-guru sekolah dasar di lingkungan kota Palangka Raya, pemilihan sekolah yang mengikuti kegiatan dilakukan secara acak/random. Metode yang digunakan dalam pengabdian ini adalah memberikan pelatihan kepada guru-guru sekolah dasar dan kemudian diadakan diskusi antar peserta dan pemateri. Biaya kegiatan pengabdian ini sepenuhnya bersumber dari APBU Universitas Muhammadiyah Palangkaraya Tahun 2015. Setelah dilaksanakan kegiatan ini, maka dapat disimpulkan bahwa para peserta pelatihan mendapatkan pengetahuan yang baru atau merefresh kembali pengetahuan yang telah mereka miliki.

Kata Kunci : Guru, Profesional 


\section{PENDAHULUAN}

\section{Analisis Situasi}

Penyelenggaraan pendidikan di sekolah dasar terdapat beberapa komponen yang saling mempengaruhui satu sama lainnya. Guru merupakan salah satu komponen penting yang ikut menentukan tinggi rendahnya kualitas pendidikan. Kehadiran guru merupakan persyaratan mutlak bagi terselenggaranya proses pembelajaran di sekolah. Peran guru sangat diharapkan mampu membimbing dan memberikan arahan mengenai pelaksanaan pembelajaran di dalam dan di luar kelas. Seorang guru memberikan arahan, instruksi, dan evaluasi kepada anak-anak didiknya dalam proses pembelajaran. Inilah yang merupakan gambaran dari pengertian "mengajar".

Secara umum, mengajar adalah menyampaikan ilmu pengetahuan kepada anakanak didik di sekolah. Namun pada kenyataannya, pengertian mengajar lebih dari itu. Mengajar tidak hanya menyampaikan ilmu pengatuan, tetapi juga melatih pola pikir anakanak didik.

Menurut Sardiman A.M. (2004) mengajar diartikan sebagai suatu aktivitas mengorganisasi atau mengatur lingkungan sebaik-baiknya dan menghubungkan dengan anak, sehingga terjadi proses belajar. Atau dikatakan, mengajar sebagai upaya menciptakan kondisi yang kondusif untuk berlangsungnya kegiatan belajar bagi para siswa. Hal senada juga dikatakan oleh Nana Sudjana (2004) mengajar adalah membimbing peserta didik dalam kegiatan belajar mengajar atau mengandung pengertian bahwa mengajar merupakan suatu usaha mengorganisasikan lingkungan dalam hubungannya dengan anak didik dan bahan pengajaran yang menimbulkan terjadinya proses belajar mengajar.

Berdasarkan pendapat para ahli di atas maka dapat disimpulkan bahwa mengajar adalah suatu aktivitas yang tersistem dari sebuah lingkungan yang terdiri dari pendidikan dan peserta didik untuk saling berinteraksi dalam melakukan suatu kegiatan sehingga terjadi proses belajar dan tujuan pengajaran tercapai.

Guru adalah salah satu unsur penting yang harus ada sesudah peserta didik. Apabila seorang guru tidak punya sikap profesional maka peserta didik yang di didik akan sulit untuk tumbuh dan berkembang dengan baik. Hal ini karena guru adalah salah satu tumpuan bagi negara dalam hal pendidikan. Dengan adanya guru yang profesional dan berkualitas maka akan mampu mencetak anak bangsa yang berkualitas pula. Kunci yang harus dimiliki oleh setiap pengajar adalah kompetensi. Kompetensi adalah seperangkat ilmu serta ketrampilan mengajar guru di dalam menjalankan tugas profesionalnya sebagai seorang guru sehingga tujuan dari pendidikan bisa dicapai dengan baik.

Sementara itu, standard kompetensi yang tertuang ada dalam Undang-Undang Nomor 14 Tahun 2005 tentang Guru dan Dosen, pada pasal 10 ayat (1) mengenai standar kualifikasi akademik serta kompetensi guru dimana peraturan tersebut menyebutkan bahwa guru profesional harus memiliki 4 kompetensi guru profesional yaitu kompetensi pedagogik dan kompetensi kepribadian, profesional serta kompetensi sosial. Dari 4 kompetensi guru profesional tersebut harus dimiliki oleh seorang guru melalui pendidikan profesi selama satu tahun. 


\section{Permasalahan}

Guru sebagai sosok yang begitu dihormati lantaran memiliki andil yang sangat besar terhadap keberhasilan pembelajaran di sekolah dan juga membantu perkembangan peserta didik untuk mewujudkan tujuan hidupnya secara optimal. Minat, bakat, kemampuan, dan potensi peserta didik tidak akan berkembang secara optimal tanpa bantuan guru. Dalam kaitan ini guru perlu memperhatikan peserta didik secara individual. Tugas guru tidak hanya mengajar, namun juga mendidik, mengasuh, membimbing, dan membentuk kepribadian peserta didik guna menyiapkan dan mengembangkan sumber daya manusia (SDM).

Akan tetapi saat ini Ironisnya kekawatiran di dunia pendidikan kini menyeruak ketika menyaksikan tawuran antar pelajar yang bergejolak dimana-mana. Ada kegalauan muncul kala menjumpai realitas bahwa guru di sekolah lebih banyak menghukum daripada memberi reward peserta didiknya. Ada kegundahan yang membuncah ketika sosok guru berbuat asusila terhadap peserta didiknya.

Kesalahan guru dalam memahami profesinya akan mengakibatkan bergesernya fungsi guru secara perlahan-lahan. Pergeseran ini telah menyebabkan dua pihak yang tadinya sama-sama membawa kepentingan dan saling membutuhkan, yakni guru dan peserta didik, menjadi tidak lagi saling membutuhkan. Akibatnya suasana belajar sangat memberatkan, membosankan, dan jauh dari suasana yang membahagiakan. Dari sinilah konflik demi konflik muncul sehingga pihak-pihak didalamnya mudah frustasi lantas mudah melampiaskan kegundahan dengan cara-cara yang tidak benar.

online : http://jurnal.umpalangkaraya.ac.id/ejurnal/pgbmu
Jauh sebelum era globalisasi informasi, profesi dan posisi guru konon dihormati.bahkan dalam berbagai upacara dan perayaan, mereka duduk di deretan utama. Namun kini wibawa para guru di mata peserta didik - peserta didik pun kian jatuh. Peserta didik masa kini , khususnya yang menduduki sekolah-sekolah menengah di kota-kota pada umumnya hanya cenderung menghormati guru karena hanya menginginkan nilai yang tinggi atau naik kelas dengan peringkat tinggi tanpa kerja keras.Sebagiannya lagi menghormati guru agar mendapatkan dispensasi maaf dan maklum apabila mereka telat meyerahklan tugas.

Sikap dan prilaku masyarakat seperti itu memang tidak sepenuhnya tanpa alasan yang bersumber dari para guru .Ada sebagian guru yang terbukti memang berpenampilan tidak mendidik. Ada yang memberi hukuman badan di luar batas normal kependidikan dan lainnya. Kelemahan lain yang juga ada pada sebagian guru adalah kerendahan tingkat kompetensi profesionalisme sebagai guru .Penguasaan terhadap materi dan metode pengajaran masih berada di bawah standar.

\section{Tujuan}

Kegiatan pengabdian kepada masyarakat ini dilakukan untuk meningkatkan profesionalisme guru agar dapat menjadi seorang guru yang profesional dan dapat memajukan mutu pendidikan di Indonesia yang saat ini mutunya masih tergolong rendah. 


\section{METODE PELAKSANAAN}

\section{Waktu dan Tempat}

Pengabdian masyarakat ini dilaksanakan pada hari kamis, 18 Februari 2016 di Aula Pimpinan Wilayah Muhammadiyah Kalimantan Tengah, di Jalan RTA Milono KM 1,5 Palangka Raya (Komplek Perguruan Muhammadiyah Palangka Raya). Tempat pengabdian ini satu lokasi dengan kampus Universitas Muhammadiyah Palangkaraya. Demi kelancaran kegiatan ini kami sebelumnya telah berkomunikasi dengan pengelola aula untuk mengatur jadwal kegiatan hingga hari pelaksanaan dan berakhirnya kegiatan.

\section{Sasaran Kegiatan}

Masyarakat sasaran dalam pengabdian ini adalah guru-guru SD yang ada di kota Palangka Raya. Guru-guru SD di Palangka Raya sebagian besar sudah memenuhi syarat kualifikasi minimum pendidikan, yaitu lulusan S-1 PGSD. Pemilihan peserta pelatihan dilakukan secara random kepada seluruh Sekolah Dasar yang ada di Palangka Raya kemudian diputuskan 10 Sekolah Dasar. Masing-masing sekolah diminta 3 orang guru mewakili sekolahnya untuk mengikuti kegiatan dengan membawa surat tugas dari sekolah masing-masing.

\section{Metode Kegiatan}

Pengabdian kepada masyarakat yang kami lakulan ini dengan bentuk pelatihan kepada guru-guru sekolah dasar tentang Guru Profesional. Pelatihan ini dilaksanakan di Aula PW Muhammadiyah Kalimantan tengah.
Pengabdian kepada masyarakat ini diawali dengan acara pembukaan, kemudian ada kata sambutan dari Ketua TIM Pengabdian dan sambutan dari Kepala LP2M sekaligus membuka secara resmi kegiatan pelatihan. Sebelum masuk kedalam materi, pelaksana mengadakan pre tes kepada seluruh peserta pelatihan dengan maksud mengetahui kemampuan awal mereka sebelum diberikan materi. Adapun materi kegiatan ini terdiri dari 4 materi yang disampaikan oleh 3 pemateri. Pemateri pertama yaitu Misyanto, M.Pd menyampaikan materi tentang kompetensi pedagogik. Kompetensi pedagogik meliputi pemahaman guru terhadap peserta didik, perancangan dan pelaksanaan pembelajaran, evaluasi hasil belajar, dan pengembangan peserta didik untuk mengaktualisasikan berbagai potensi yang dimilikinya.

Pemateri kedua yaitu Dian Lufia Rahmawati, M.Pd menyampaikan materi tentang kompetensi kepribadian dan kompetensi sosial. Kompetensi kepribadian meliputi bagaimana guru memiliki akhlak yang mulia, berwibawa serta dihormati oelh peserta didik. Kompetensi sosial meliputi guru harus mampu berkomunikasi yang baik kepada peserta didik, guru yang lain maupun kepada orang tua peserta didik.

Pemateri ketiga yaitu Agung Riadin, S.Pd.I., M.Pd menyampaikan materi tentang kompetensi profesional. Kompetensi profesional meliputi guru harus menguasai materi ajar yang akan di ajarkan kepada peserta didiknya. Setelah penyampaian materi oleh masing-masing pemateri, dilakukan adanya tanya jawab yang dipandu oleh Ilham, M.Pd sebagai moderator pada acara pelatihan. 


\section{Solusi yang Ditawarkan}

Pelatihan guru profesional merupakan salah satu upaya yang dapat dilakukan untuk meningkatkan profesionalisme guru agar dapat menjadi seorang guru yang profesional dan dapat memajukan mutu pendidikan di Indonesia yang saat ini mutunya masih tergolong rendah. Materi yang diberikan kepada peserta adalah tentang 4 kompetensi guru profesional sebagaimana yang tercantum dalam PP RI No. 19/ 2005 tentang standar Nasional Pendidikan pasal 28, dinyatakan bahwa pendidik adalah agen pembelajaran yang harus memiliki empat jenis kompetensi, yakni kompetensi pedagogik, kepribadian, professional, dan sosial.

Kompetensi Pedagogik terdiri dari beberapa kompetensi inti guru yang berkenaan dengan pemahaman terhadap peserta didik, pengelolaan pembelajaran yang mendidik, dan berbagai pengembangan yang mendidik. Kompetensi inti guru dalam pedagogik ini meliputi:

1) Menguasai karakteristik peserta didik dari aspek fisik, moral, social, cultural,emosional dan intelektual.

2) Menguasai teori belajar dan prinsip-prinsip pembelajaran yang mendidik

3) Mengembangkan kurikulum yang terkait dengan bidang pengembangan yang diampu

4) Menyelenggarakan kegiatan pengembangan yang mendidik

5) Memanfaatkan tehnologi informasi dan komunikasi untuk kepentingan penyelenggaraan kegiatan pengembangan yang mendidik

6) Menfasilitasi pengembangan potensi peserta didik untuk mengaktualisasikan berbagai potensi yang dimiliki
7) Berkomunikasi secara efektif, empatik, dan santun dengan peserta didik

8) Menyelenggarakan penilaian dan evaluasi proses dan hasil belajar

9) Memanfaatkan hasil penilaian dan evaluasi untuk kepentingan pembelajaran

10) Melakukan tindakan reflektif untuk peningkatan kualitas pembelajaran

Kompetensi kepribadian terdiri dari beberapa kompetensi inti guru yang mencerminkan kepribadian yang mantap, stabil, stabil, dewasa, arif dan berwibawa, menjadi teladan bagi peserta didik, dan berahlak mulia .Kompetensi inti guru dalam kepribadian ini meliputi:

1) Bertindak sesuai dengan norma agama, hukum, social dan kebudayaan nasional Indonesia

2) Menampilkan diri sebagai pribadi yang jujur dan berakhlak mulia, teladan bagi peseerta didik dan masyarakat

3) Menampilkan diri sebagai pribadi yang mantap, stabil, dewasa, arif, dan berwibawa

4) Menunjukkan etos kerja, tanggung jawab yang tinggi, rasa bangga menjadi guru dan rasa percaya diri.

5) Menjujung tinggi kode etik profesi guru

Kompotensi Profesional meliputi berbagai kompotensi inti guru yang berkenaan dengan penguasaan materi pembelajaran bidang studi secara luas dan mendalam yang mencakup penguasaan substansi isi materi kurikulum mata pelajaran di sekolah dan substansi keilmuan yang menaungi materi kurikulum tersebut, serta menambah wawasan keilmuan sebagai guru. Kompotensi inti guru dalam kompotensi professional ini mencakup : 
1) Menguasai materi, struktur, konsep, dan pola piker keilmuan yang mendukung mata pelajaran yang diampu.

2) Mengembangkan materi pembelajaran yang diampu secara kreatif

3) Menguasai standar kompotensi dan kompotensi dasar mata pelajaran atau bidang pengembangan yang diampu.

4) Mengembangkan keprofesionalan secara berkelanjutan dengan melakukan tindakan reflektif

5) Memanfaatkan tekhnologi informasi dan komunikasi untuk berkomunikasi dan mengembangkan diri.

Kompotensi social meliputi berbagai kompoteninti gurur sebagai bagian dari masyarakat untuk berkomunikasi dan bergaul secara efektif dengan peserta didik, sesama didik, tenaga kependidikan. Orang tua / wali peserta didik, dan masyarakat sekitar. Kompotensi inti guru dalam bidang sosial ini meliputi :

1) Bersikap inklusif, bertindak obyektif, serta tidak diskriminatif karena pertimbangan jenis kelamin, agama, ras, kondisi fisik, latar belakang keluarga, dan status social ekonomi.

2) Berkomunikasi secara efektif, empatik, dan santun dengan sesame pendidik, orang tua, dan masyarakat.

3) Beradaptasi di tempat bertugas di seluruh wilayah Republik Indonesia yang memiliki keragaman social budaya

4) Berkomunikasi dengan komunitas profesi sendiri dan profesi lain secara lisan dan tulisan atau bentuk lain.

\section{HASIL DAN PEMBAHASAN}

Permasalahan-permasalahan yang telah dijelaskan di pendahuluan, cepat atau lambat akan menjatuhkan prestise (wibawa yang berkenaan dengan prestasi), khususnya prestise profesionalisme para guru. Ironisnya, kemerosotan prestise profesional sering diikuti dengan kemerosotan prestise sosial dan prestise material. Yaitu bahwa para guru kini kurang dihargai masyarakat.

Pelatihan guru profesional merupakan salah satu upaya yang dapat dilakukan untuk meningkatkan profesionalisme guru agar dapat menjadi seorang guru yang profesional dan dapat memajukan mutu pendidikan di Indonesia yang saat ini mutunya masih tergolong rendah. Materi yang diberikan kepada peserta adalah tentang 4 kompetensi guru profesional sebagaimana yang tercantum dalam PP RI No. 19/2005 tentang Standar Nasional Pendidikan pasal 28, dinyatakan bahwa pendidik adalah agen pembelajaran yang harus memiliki empat jenis kompetensi, yakni kompetensi pedagogik, kepribadian, professional, dan sosial. Hal tersebut yang menjadi alasan TIM memilih kegiatan pelatihan "Guru Profesional bagi Guru SD/MI di Palangkaraya" sebagai bentuk pengabdian kepada masyarakat.

Palangka Raya, 18 Februari 2016 TIM Pengabdian dosen UM Palangkaraya melakukan kegiatan pengabdian bertempat di Aula PW Muhammadiyah Kalimantan Tengah. Sebelum dimulainya acara sudah terlihat begitu antusiasnya peserta pelatihan, banyak dari mereka yang sudah tiba di tempat acara 1 jam sebelum acara dimulai. Selama kegiatan 
berlangsung begitu terlihat keaktifan peserta pelatihan dalam sesi diskusi kepada masingmasing pemateri. Banyak diantara mereka yang memberikan masukan positif tentang kegiatan pengabdian kepada masyarakat ini. Dari hasil postest yang diberikan TIM di akhir acara kegiatan terlihat perubahan yang signifikan dari peserta pelatihan. Data hasil pretes dan postest dapat dilihat pada tabel di bawah ini.

Tabel Data Hasil Pretest dan Postest

\begin{tabular}{|c|c|c|c|}
\hline No & Nama & Pretest & Postest \\
\hline 1 & NYLFA MOMPO PERINA S.S. S.Th & 60 & 80 \\
\hline 2 & NAILUL PAUJIAH, S.Pd & 80 & 100 \\
\hline 3 & YEDI SURYADI, A.Ma & 70 & 80 \\
\hline 4 & LAURE, S.Pd & 50 & 70 \\
\hline 5 & CENCEN, S.Pd & 60 & 70 \\
\hline 6 & ERVINA LING LING, S.Pd & 50 & 80 \\
\hline 7 & PENDI, S.Pd & 70 & 80 \\
\hline 8 & SUHARTI, S.Pd & 90 & 100 \\
\hline 9 & MAIMUNAH, A.Ma & 60 & 70 \\
\hline 10 & ETI HARYATI, S.Pd & 60 & 80 \\
\hline 11 & RATNAWATY, S.Pd & 50 & 70 \\
\hline 12 & NENI PAHLAWATY & 80 & 80 \\
\hline 13 & MARID ACEH S. MASAL, S.Pd & 60 & 80 \\
\hline 14 & ROSELI & 70 & 80 \\
\hline 15 & MARIANI, S.Pd & 80 & 90 \\
\hline 16 & NYAMIATUN, S.Pd & 70 & 100 \\
\hline 17 & ICAE, S.Pd & 70 & 80 \\
\hline 18 & DEWI GALIS, S.Pd & 40 & 70 \\
\hline 19 & TITIE, S.Pd & 60 & 70 \\
\hline 20 & RUSDIANA, S.Pd & 90 & 100 \\
\hline 21 & AMAN YATINI, S.Pd & 70 & 70 \\
\hline 22 & NICHALANI SAKA, S.Pd & 90 & 100 \\
\hline 23 & MASMUDAH, S.Pd & 80 & 90 \\
\hline 24 & SRI MULYANTI, S.Ag & 80 & 90 \\
\hline 25 & SAIUN, S.HI & 90 & 90 \\
\hline 26 & ULIA ULFAH, S.Pd & 60 & 100 \\
\hline 27 & ARPIATI DASEK, S.Pd & 40 & 70 \\
\hline
\end{tabular}

online : http://jurnal.umpalangkaraya.ac.id/ejurnal/pgbmu

\begin{tabular}{llll}
\hline 28 & ELIWATI, M.Pd & 70 & 80 \\
\hline 29 & SANDRA ARYANI K., S.Pd & 70 & 80 \\
\hline
\end{tabular}

Berdasarkan data di atas masing-masing peserta memiliki peningkatan yang berbeda namun signifikan. Setelah diberikan materi-materi tentang komptensi-kompetensi keprofesionalan guru, tiap peserta mendapatkan pengetahuan yang baru atau merefresh kemabali pengatahuan yang mereka miliki sehingga dapat mengembangkan dan meningkatkan keprofesionalan mereka.

\section{SIMPULAN DAN SARAN}

\section{Simpulan}

Pelatihan guru profesional merupakan salah satu upaya yang dapat dilakukan untuk meningkatkan profesionalisme guru agar dapat menjadi seorang guru yang profesional dan dapat memajukan mutu pendidikan di Indonesia. Materi yang diberikan kepada peserta adalah tentang 4 kompetensi guru profesional sebagaimana yang tercantum dalam PP RI No. 19/2005 tentang Standar Nasional Pendidikan pasal 28, dinyatakan bahwa pendidik adalah agen pembelajaran yang harus memiliki empat jenis kompetensi, yakni kompetensi pedagogik, kepribadian, professional, dan sosial.

Setelah diberikan materi-materi tentang komptensi-kompetensi keprofesionalan guru, tiap peserta mendapatkan pengetahuan yang baru atau merefresh kemabali pengatahuan yang mereka miliki sehingga dapat mengembangkan dan meningkatkan keprofesionalan mereka. 


\section{Saran}

\begin{tabular}{|c|c|c|}
\hline Kami & TIM & pengabdian \\
\hline asyarakat & memilki & keinginan jika \\
\hline lanatka & & kesempatan \\
\hline lan & t & pengabdian \\
\hline
\end{tabular}

masyarakat dari LP2M akan melanjutkan dengan kegiatan pembinaan secara langsung kepada sekolah dasar yang terpilih sebagai peserta binaan nantinya. Bagi peserta yang telah diberikan pelatihan diharapkan dapat mengaplikasikan ilmu yang telah didapat dalam proses pembelajaran di sekolah masing-masing.

\section{DAFTAR PUSTAKA}

Nana Sudjana, (2004), Dasar-Dasar Proses Belajar Mengajar, Bandung : Sinar Baru Algensindo.

Sardiman, A.M. (2004), Interaksi dan Motivasi Belajar Mengajar, Jakarta : PT Raja Grafindo Persada.

Tim Penyusun, 2014, Panduan Penyusunan Usulan Penelitian dan Pengabdian Kepada Masyarakat UM Palangkaraya, Palangka Raya : LP2M.

Undang-Undang Nomor 14 Tahun 2005 tentang Guru dan Dosen, pada pasal 10 ayat (1) tentang Kompetensi Guru 